\title{
Size of Inoculum and Carbon Metabolism in some Aspergillus Species
}

\author{
By J. MEYRATH AND A. F. MCINTOSH \\ Department of Applied Microbiology and Biology, The Royal \\ College of Science and Technology, Glasgow
}

(Received 4 March 1963)

\begin{abstract}
SUMMARY
The effect of size of inoculum on growth and carbon metabolism of Aspergillus oryzae and several other Aspergillus species was studied. During most of the development a culture from a small inoculum, as compared to a large-inoculum culture, had a smaller specific rate of respiration, formed more ethanol and acids per unit weight of mycelium, and metabolized more carbohydrate to produce a given amount of growth. It seems that this inefficient utilization of carbon source is due not only to the production of a smaller amount of energy but also to an inefficient utilization of the released energy. The higher degree of inefficiency appears to be the result of the aging process which a small-inoculum culture undergoes during its development to the stage of growth of a young largeinoculum culture; the latter also shows a decrease in efficiency during cultivation.
\end{abstract}

\section{INTRODUCTION}

In earlier publications it was reported that certain growth characteristics of cultures of Aspergillus oryzae were influenced by the size of the inoculum (Meyrath, $1962 a, 1963)$. Conidia were then mainly used as inoculum; a large and a small inoculum comprised usually $4 \times 10^{7}$ and $4 \times 10^{3}$ conidia $/ 100 \mathrm{ml}$. substrate, respectively (corresponding to dry weights of organism of about 0.8 and $0.8 \times 10^{-4} \mathrm{mg}$.). Alternatively, filamentous mycelium was used as inoculum, the corresponding amounts being about 10 and $10^{-3} \mathrm{mg}$. dry wt. mycelium/100 ml. culture. In many substrates rate of growth and maximum yield decreased when a small inoculum was used. Under the particular conditions of using substrates either poor in trace elements or rich in carbohydrate the effects of inoculum size were very marked and were even more pronounced when both conditions obtained simultaneously. The effect on maximum yield of organism was always more pronounced in submerged cultures with vigorous agitation and aeration than in stationary or shaken cultures. It may also be mentioned here that the pronounced effects obtained in traceelement-poor substrates were not due to a carry-over of trace elements contained in large inocula.

To understand the phenomena observed with different sizes of inocula, the influence of size of inoculum on characters other than mycelium formation was examined. The present work deals mainly with the effect of size of inoculum on the metabolism of carbon sources. 


\section{METHODS}

Organism and inoculum. The Aspergillus oryzae strain used for most of the work described was that used previously (Meyrath, 1962a, 1963). This organism and the strain of Aspergillus flavus used were stock strains in the Department of Agricultural Bacteriology and Fermentation, Swiss Federal Institute of Technology, Zürich. The other Aspergillus strains mentioned were obtained from the Centraalbureau voor Schimmelcultures, Baarn, Netherlands. Conidia were used as inoculum, and were at first produced on malt wort agar slopes by incubation at $25^{\circ}$ for 7-14 days. Later it was found that sporulation was heavier and more reliable under the same conditions when the substrate described below was used. In neither case did size of inoculum influence the extent of formation of conidia. A suspension of conidia in sterile distilled water was filtered through sterile absorbent cotton wool. The conidia were washed three times by centrifugation, counted in a haemocytometer and diluted as required. Their germinative ability was determined on malt wort agar plates after incubation for 3 days at $25^{\circ}$. This value has remained consistently at about $\mathbf{5 0} \%$ over several years of testing.

\section{Table 1. Composition of the substrates}

All substrates contained (g./1.): carbohydrate (starch 10; if otherwise, kind and concentration are specified in the text); $\left(\mathrm{NH}_{4}\right)_{2} \mathrm{SO}_{4}, 1 ; \mathrm{MgSO}_{4} \cdot 7 \mathrm{H}_{2} \mathrm{O}, 0 \cdot 3$. The other components are as indicated below.

\begin{tabular}{|c|c|c|c|c|}
\hline $\mathbf{A}$ & Al & $\begin{array}{c}\text { A3 } \\
\text { g. } / 1 .\end{array}$ & A4 & A5 \\
\hline $\begin{array}{l}4.73 \\
4.54\end{array}$ & $\begin{array}{l}4.73 \\
4.54\end{array}$ & $\begin{array}{r}9.46 \\
9.08 \\
\mathrm{mg} \cdot / 1\end{array}$ & $\begin{array}{l}4.73 \\
4.54\end{array}$ & $\begin{array}{l}9 \cdot 46 \\
9.08\end{array}$ \\
\hline $15 \cdot 0$ & $15 \cdot 0$ & $15 \cdot 0$ & $15 \cdot 0$ & 2.5 \\
\hline 0.5 & - & - & 0.05 & 0.2 \\
\hline 0.5 & - & - & 0.05 & 0.2 \\
\hline $5 \cdot 0$ & - & - & 0.5 & Varied \\
\hline $10 \cdot 0$ & - & - & $1 \cdot 0$ & - \\
\hline
\end{tabular}

Substrates. The substrates used were in part those described elsewhere (Meyrath, 1963). Their composition is given in Table 1.

The sporulation substrate contained (g./l.): starch, $40 ;\left(\mathrm{NH}_{4}\right)_{2} \mathrm{SO}_{4}, 8 ; \mathrm{MgSO}_{4}$. $7 \mathrm{H}_{2} \mathrm{O}, 0 \cdot 3 ; \mathrm{Na}_{2} \mathrm{HPO}_{4}, 35 \cdot 5 ; \mathrm{KH}_{2} \mathrm{PO}_{4}, 34 ; \mathrm{FeCl}_{3} .6 \mathrm{H}_{2} \mathrm{O}, 0.003$.

All chemicals were of Analar or Pro analysi (Merck) quality with the exception of the sucrose which was a commercial product.

The $\mathrm{pH}$ value of the media described is approximately $6 \cdot 8$; they undergo no significant change of $\mathrm{pH}$ value during sterilization.

Starch when used was poured into a boiling solution of the remaining constituents; the boiling was maintained for a few minutes, then the cooled solution made up to volume. When glucose was used, the mineral solution was autoclaved separately. When starch or sucrose was used, minerals and carbohydrate were sterilized together, starch medium by autoclaving, sucrose medium by tyndallization. Tyndallization of small amounts of substrate was by steaming for $\mathbf{3 0} \mathrm{min}$. on $\mathbf{3}$ consecutive days. 
Procedure. Submerged cultures were grown in 51 . quantities in 6 l. triple neck flasks, fitted with a Vibro-Mix stirrer (AG. für Chemie-Apparatebau, Männedorf, Zürich, Switzerland) which agitated the substrate by a vibrating stirrer; the degree of agitation could be adjusted by the amplitude of the vibrations and the size of the stirrer. The culture was aerated at a flow rate of about $500 \mathrm{ml} . / \mathrm{min}$. Homogeneous growth of dispersed mycelium was obtained. The substrate received an inoculum of $2 \times 10^{7}$ conidia $/ 100 \mathrm{ml}$. medium (large-inoculum experiments), or $4 \times 10^{3}$ conidia/ $100 \mathrm{ml}$. (small-inoculum experiments), the inoculum being $50 \mathrm{ml}$. in each case. Stationary cultures were grown in $50 \mathrm{ml}$. or $100 \mathrm{ml}$. conical flasks containing 20 or $25 \mathrm{ml}$. medium, respectively. Each flask was inoculated with $1 \mathrm{ml}$. of suspension containing $10^{7}$ conidia (large-inoculum experiments) or $10^{3}$ conidia (small-inoculum experiments).

The temperature of incubation was $25^{\circ}$ in all experiments.

From submerged cultures, with filamentous mycelium formation, samples of 10-500 ml. were taken so that the mycelium dry weight of each was not less than $5 \mathrm{mg}$.; estimations were done in duplicate or triplicate. With stationary cultures, duplicate or triplicate sample flasks were taken. The mycelium in both cases was collected on nylon filters in Büchner funnels. After repeated alternate washing with water and pressing with a rubber bung, pellets were made, dried at $104^{\circ}$ overnight, weighed and the weights at each stage calculated on a basis of mg. dry wt. mycelium $/ 100 \mathrm{ml}$. culture.

Oxygen uptake was measured manometrically or volumetrically, and output of carbon dioxide manometrically. Homogeneous filamentous mycelium from VibroMix cultures was used for these experiments; mycelium washed and pressed as described, but undried, was suspended in water or phosphate buffer (Sörensen, M/15, pH 6.8). The gas exchanges of unwashed cell material were also studied with mycelium taken directly from the culture or from material concentrated on a nylon filter and suspended in culture filtrate. To ensure a suitable working range, the mycelium wet weight of duplicate samples was determined and dilutions of the test samples made. The manometric experiments were done with about 2 to $\mathbf{3} \mathrm{mg}$. dry wt. mycelium/flask. With the volumetric technique between 20 and $30 \mathrm{mg}$. dry wt. mycelium/flask were used; the mycelium was tested within about $3 \mathrm{hr}$. from the time of sampling.

Flasks (13-23 ml.) for manometric measurement received $2 \mathrm{ml}$. mycelial suspension in the main compartment and $0.5 \mathrm{ml}$. glucose solution $(10 \mathrm{mg} . / \mathrm{ml}$.) or buffer in the side arm. For the estimation of oxygen uptake, $0.2 \mathrm{ml}$. of $20 \% \mathrm{KOH}$ was placed in the centre well the inner rim of which was coated with lanolin to prevent creeping of the alkali. The manometers were shaken at $103 \mathrm{cyc} . / \mathrm{min}$.; amplitude $4.2 \mathrm{~cm}$.; in other respects the procedure described by Umbreit, Burris \& Stauffer (1949) was followed. Flasks for volumetric measurement of about $100 \mathrm{ml}$. capacity fitted with a rotatable side arm were attached to $10 \mathrm{ml}$. burettes by rubber bungs; they received $20 \mathrm{ml}$. mycelial suspension in the main compartment, $1 \mathrm{ml}$. glucose solution $(20 \mathrm{mg} . / \mathrm{ml}$.) or buffer in the side arm and $1 \mathrm{ml} .20 \% \mathrm{KOH}$ in the centre well (treated as for the manometric flasks); for further details see Nilsson (1941). All gas exchange experiments were done in duplicate at $25^{\circ}$. Carbon dioxide was estimated by the direct method of Warburg. With buffer or substrate as suspending medium for the mycelium, the $\mathrm{pH}$ value was determined and the solubility 
of carbon dioxide calculated according to the formula $\alpha^{\prime}=0.759$ [antilog $(\mathrm{pH}-6 \cdot 34)+1], \alpha^{\prime}$ indicating the solubility of carbon dioxide at the given $\mathrm{pH}$.

The gas exchange reactions were usually recorded at $15 \mathrm{~min}$. intervals over $3 \mathrm{hr}$. In all cases zero order reactions were obtained, with hardly any induction phase.

Sugar was estimated after Stiles, Peterson \& Fred (1926); before assay, starch was hydrolysed by heating in a boiling water bath for $1 \mathrm{hr}$. in $\mathrm{N}-\mathrm{HCl}$ and the mixture neutralized with $\mathrm{NaOH}$.

Ethanol was estimated after Maxon \& Johnson (1953). Although not specific, this method was used because ethanol appears to be the only volatile oxidizable compound present in measurable amount in cultures of Aspergillus oryzae (Tamiya, 1942). $\mathrm{pH}$ values were determined by a calomel/glass electrode system.

\section{RESULTS}

\section{Oxygen uptake and carbon dioxide output}

It has been reported that the specific rate of oxygen uptake (oxygen uptake/unit weight cell material/time) by filamentous fungi, actinomycetes and bacteria decreases with increasing age of the culture (Tamiya, 1942; Rolinson, 1952; Somm, 1953; Di Marco, 1956; Temperli, 1956; Müller, 1957). So far, however, it does not appear to have been shown that this holds during the phase of constant multiplication rate, i.e. the exponential phase, where a regular increase of cellular material is expected to take place. When a submerged culture of Aspergillus oryzae suitably provided with nutrients is kept under a sufficiently vigorous degree of aeration and agitation, it is possible to establish exponential growth over a wide range of the growth curve (Meyrath, 1963). When cultures from large inocula are examined under conditions of unrestricted growth, young cultures (up to $32 \mathrm{hr}$.) show a high specific rate of oxygen uptake $\left(\mathrm{QO}_{2}=100-220 \mu \mathrm{l}\right.$. $\mathrm{O}_{2} / \mathrm{mg}$. dry wt. mycelium/hr. $)$, whereas older cultures are characterized by a much smaller value (30-56 $\mu \mathrm{l} . \mathrm{O}_{2} / \mathrm{mg}$. dry wt. mycelium/hr.). One set of results is shown in Fig. 1, where the growth curves obtained from large and small inocula are represented. In the semi-logarithmic plot the difference in maximum yield of cell material between large- and small-inoculum cultures appeared to be small, but was in fact appreciable. The large-inoculum culture produced $430 \mathrm{mg}$. dry wt. mycelium $/ 100 \mathrm{ml}$. medium and the small-inoculum culture $260 \mathrm{mg}$. dry wt. mycelium/100 ml. medium. Table 2 is a compilation of data on oxygen uptake from experiments under various conditions. When small-inoculum cultures were grown under the same conditions, mycelium was produced which gave much lower rates of specific oxygen uptake at all stages of measurable growth. The results of one set of experiments in the phase of exponential growth is shown in Fig. 1; further data obtained under other conditions revealed a similar phenomenon. One point to be stressed is that readings of oxygen uptake for large- and small-inoculum cultures were taken at equally low values of mycelium content.

The results suggest that mycelium from small-inoculum cultures at all stages of measurable growth behaved like mycelium from large-inoculum cultures at late stages of growth. It appears that small-inoculum cultures underwent an aging process (leading to a diminished rate of oxygen uptake) during the prolonged time they took to reach the same content of mycelium as in large-inoculum cultures at 
early stages of growth. In these particular substrates, with submerged cultivation, the rate of multiplication remained constant for large-inoculum and small-inoculum cultures (Fig. 1; see also Meyrath, 1963) although the specific rate of oxygen uptake decreased. This means that in advanced stages of growth less oxygen was required to form a given weight of mycelium. If the amount of energy required for synthesis of unit weight of mycelium was constant during exponential growth, and if a given amount of oxygen taken up released a proportional amount of energy for cellular synthesis, then it might be assumed that in advanced stages of growth the required energy is made up by anaerobic processes. This view was expressed in connexion with anaerobic spoilage of fruit juices by moulds (Meyrath, 1962b). The result of this anaerobic metabolism is an inefficient utilization of carbon source. Since smallinoculum cultures are characterized by a low specific rate of oxygen uptake during



Fig. 1



Fig. 2

Fig. 1. The accumulation of mycelium of Aspergillus oryzae and the specific oxygen uptake at different stages of growth, from large ( - - ) and small $(\mathrm{O}-\mathrm{O})$ inocula.

Fig. 2. Specific ethanol production of Aspergillus oryzae in stationary cultures with substrate A 3, at various stages of growth using large ( - ) and small $(\mathrm{O}-\mathrm{O})$ inocula.

Table 2. Specific rate of oxygen uptake and respiratory quotient $(R Q)$ of mycelium from submerged large-inoculum cultures of Aspergillus oryzae at various stages of growth.




measurable growth, they may be expected to utilize the carbon source less efficiently than large-inoculum cultures; the latter are characterized by a high specific rate of oxygen uptake in early measurable growth, an appreciable part of total growth in this instance.

That anaerobic dissimilation (anoxybiontic fermentation, according to Bernhauer) may take place to a larger extent in older cultures is indicated by the increase of the respiratory quotient ( $R Q)$ at some stages of growth (Table 2). Further evidence of this phenomenon is given below, together with the role which it plays when the size of the inoculum is varied.

\section{Efficiency of utilization of the carbon source}

Ethanol is a common fermentation product of Aspergillus oryzae (Tamiya, 1942) and its accumulation is necessarily accompanied by evolution of carbon dioxide without uptake of oxygen, leading to a higher respiratory quotient as shown previously. In the present work ethanol was estimated in stationary cultures, using

Table 3. Influence of various concentrations of zinc on the ratio dry weight of mycelium from large inoculum: dry weight of mycelivm from small inoculum at three different stages of growth of Aspergillus oryzae

\begin{tabular}{|c|c|c|c|c|c|c|}
\hline \multirow{2}{*}{$\begin{array}{l}\text { Time of } \\
\text { cultivation } \\
\text { (days) }\end{array}$} & \multicolumn{6}{|c|}{ Concentration of zinc $(\mu \mathrm{g} . / 100 \mathrm{ml})}$. \\
\hline & 0 & $\mathbf{0} \cdot \mathbf{3}$ & 1 & $\mathbf{3}$ & 10 & 30 \\
\hline $7-8$ & $4-82$ & $4 \cdot 48$ & 3.07 & $2 \cdot 63$ & $1 \cdot 88$ & 1.78 \\
\hline $10-11$ & $2 \cdot 76$ & $2 \cdot 85$ & $2 \cdot 2$ & $1 \cdot 50$ & $1 \cdot 33$ & $1 \cdot 41$ \\
\hline 22-23 & $1 \cdot 65$ & $1 \cdot 69$ & 1.33 & $1 \cdot 19$ & $1 \cdot 25$ & 1.22 \\
\hline
\end{tabular}

substrates A 3 (no trace elements added except Fe) and A 5 (different amounts of $\mathrm{Zn}$ and other trace elements added). Figure 2 shows that the ratio by weight of ethanol to mycelium (specific ethanol production), determined at various stages of the linear phase of growth, was always higher when a small inoculum was used. The growth curves corresponding to this experiment showed that a much smaller growth rate in the linear phase was evident when the inoculum was small. Even in the presence of trace elements (substrate A 5) the specific ethanol production was always higher in small-inoculum cultures than in large-inoculum cultures over a growth range of about 45-375 mg. dry wt. mycelium/100 ml. (Fig. 3). Beyond this range, when 3 or $30 \mu \mathrm{g}$. $\mathrm{Zn}$ were added/100 ml., about equal or slightly smaller specific amounts of ethanol were formed in the small-inoculum culture. In this substrate ethanol formation did not increase in late stages of growth contrary to the results obtained with substrate A3.

The general effect of zinc, as well as its particular effect on ethanol production, may be mentioned here. It has been reported that trace elements counteract the effects of size of inoculum (Meyrath, 1962 $a, 1963$ ). It can be seen from Table 3 that among the trace elements used in these and other experiments, zinc (1-30 $\mu \mathrm{g}$./ $100 \mathrm{ml}$.) was particularly important in diminishing the effects of inoculum size. The ratio of dry wt. mycelium from large-inoculum to that from small-inoculum culture (dwm. large/dwm. small), determined at various stages of growth, decreased steadily with increasing concentration of zinc. The decrease of this ratio was due to the fact that zinc stimulated the growth of small-inoculum cultures more strongly 
than that of large-inoculum cultures (see Fig. 4). Addition of zinc not only decreased the ratio dwm. large/dwm. small, but also suppressed specific ethanol production over the major part of the culture development (Fig. 3).

Although ethanol appears to be the major fermentation product of Aspergillus oryzae under the present conditions of testing, there was some formation of organic acids when the carbohydrate concentration was higher than $10 \mathrm{~g}$./l. (at $1 \mathrm{~g}$. ammonium sulphate/1.). Aspergillus oryzae and five other strains of Aspergillus were examined to discover to what extent this property was dependent on inoculum size.

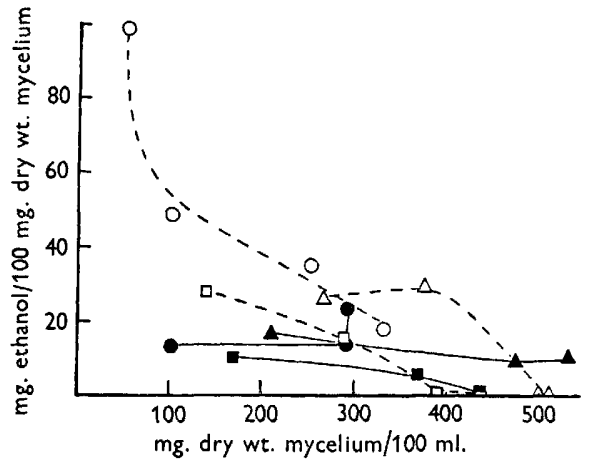

Fig. 3



Fig. 4

Fig. 3. Specific ethanol production by Aspergillus oryzae in stationary cultures with substrate A5 at various stages of growth.

$\begin{array}{ccc}\mu \mathrm{g} . \mathrm{Zn} / 100 \mathrm{ml} . & \text { large inoculum } & \text { small inoculum } \\ \mathbf{0} & - & \square-O \\ 3 & -\square & \square-\square\end{array}$

Fig. 4. Growth of Aspergillus oryzae in stationary cultures with substrate A5.

\begin{tabular}{|c|c|c|}
\hline$\mu \mathrm{g} . \mathrm{Zn} / 100 \mathrm{ml}$. & large inoculum & small inoculum \\
\hline $\mathbf{0}$ & - & $0-0$ \\
\hline $0 \cdot 3$ & - & $D-D$ \\
\hline 1 & $\Delta-\Delta$ & $\triangle-\triangle$ \\
\hline 3 & $\square-\square$ & $\square-\square$ \\
\hline 10 & $\bar{\nabla}-\bar{\nabla}$ & $\bar{\nabla}-\bar{\nabla}$ \\
\hline 30 & $1-1$ & (1) \\
\hline
\end{tabular}

Figure 5 shows that in substrate A 1 ( $80 \mathrm{~g}$. sucrose/l.) production of organic acids at the various stages of growth was higher in small-inoculum cultures. All strains showed the typical effects of inoculum size, i.e. decreased rate of growth in the linear phase and decreased maximum yield of mycelium when small inocula were used (Fig. 6). Aspergillus oryzae reacted more strongly to changes in inoculum size than did the other Aspergillus species examined. Since the production of organic acids is a lowenergy-yielding process, the same conclusion is reached as with the studies on production of ethanol and carbon dioxide, and on oxygen uptake, namely, a smallinoculum culture is less efficient than a large-inoculum culture in its use of the available carbohydrate as energy source. This comparative inefficiency (with increased formation of fermentation products) should have its counterpart in the disappearance of the carbon source supplied. Figure 7 shows that a small-inoculum culture used more starch to form a given amount of mycelium at all stages of growth 


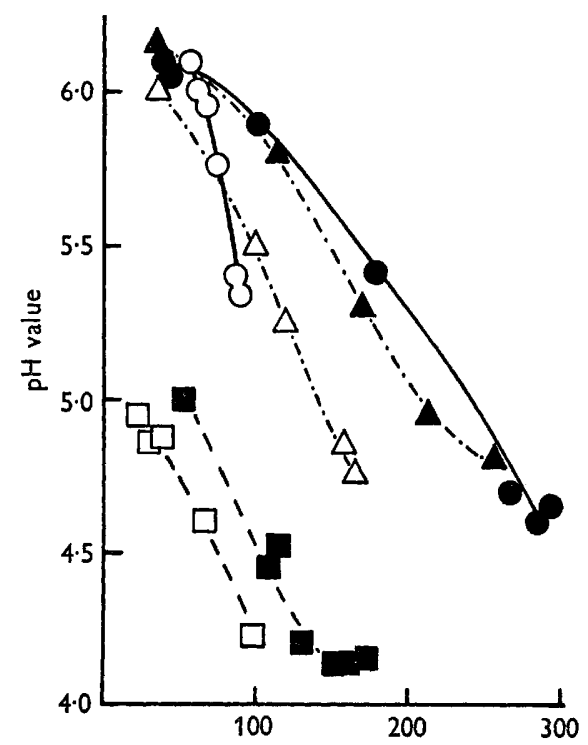

$\mathrm{mg}$. dry wt. mycelium $/ 100 \mathrm{ml}$.

$a$

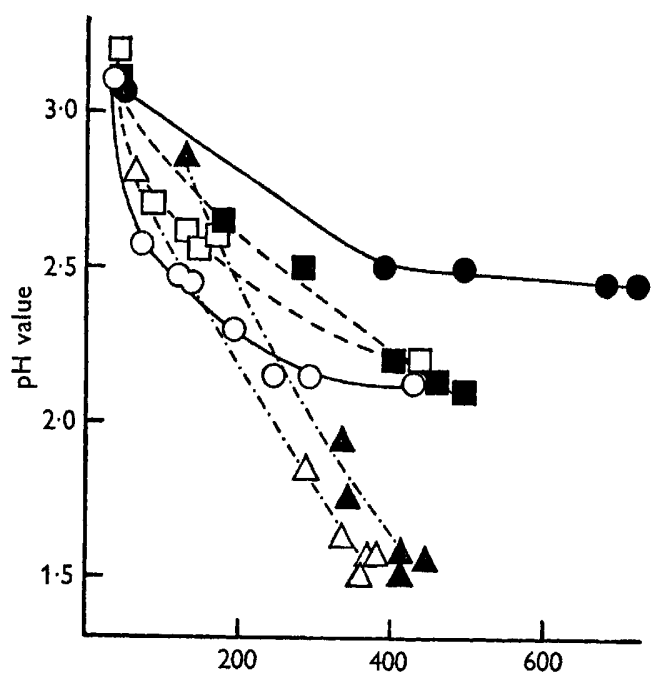

$\mathrm{mg}$. dry wt. mycelium $/ 100 \mathrm{ml}$.

$b$

Fig. 5. Production of acids (measured by decrease in $\mathrm{pH}$ value) by several Aspergillus strains at various stages of growth.

a Aspergillus oryzae

Aspergillus flavus

Aspergillus niger NRRL3

b Aspergillus niger (Kluyver strain for citric acid)

Aspergillus niger NRRL 337

Aspergillus niger ATCC 6276

large inoculum small inoculum



$\mathrm{O}-\mathrm{O}$

$\triangle-\triangle$

-10

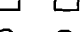

$\mathrm{O}-\mathrm{O}$

$-1$

$\triangle-\triangle$



$a$

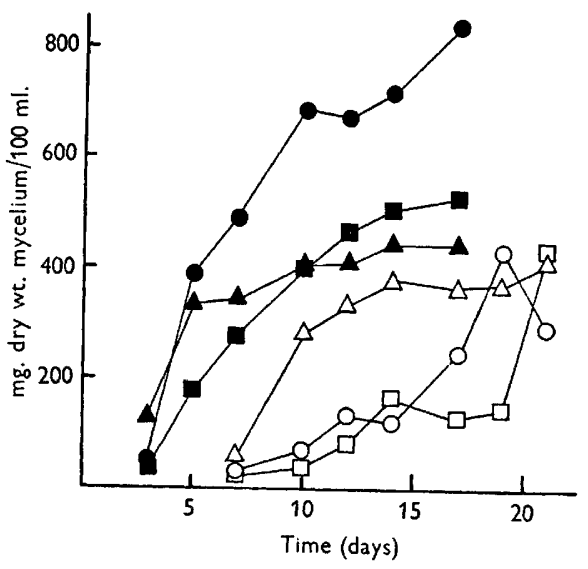

$b$

Fig. 6. Growth of various Aspergillus strainsi n stationary cultures using large and small inocula (symbols as for Fig. 5). 
in substrate A 4. A similar phenomenon was observed in substrate A. In both cases all the starch was metabolized at the point where maximum yield of mycelium was attained. The result of this is that large-inoculum cultures give a higher maximum yield of mycelium than small-inoculum cultures.

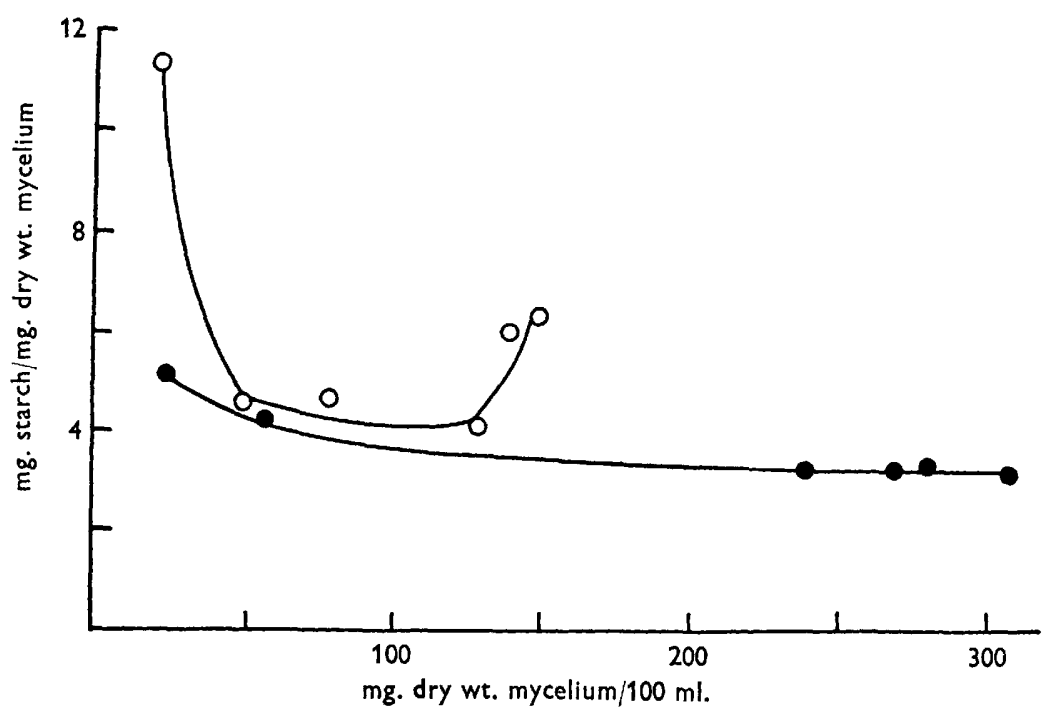

Fig. 7. Specific utilization of starch by Aspergillus oryzae at various stages of growth under submerged cultivation using large (-) and small $(0-0)$ inocula.

\section{DISCUSSION}

In this paper and elsewhere (Meyrath, 1962 a, 1963; McIntosh \& Meyrath, 1963) it has been shown that the effects of inoculum size on various growth properties of Aspergillus oryzae can be very pronounced. Use of organisms which react less strongly to a variation in size of inoculum, or use of substrates rich in trace elements (which depress the phenomena described), may have resulted in effects so small that they have been overlooked or left unrecorded by other workers. However, the five other strains of Aspergillus tested did show a response to change in size of inoculum although not quite as strongly as did Aspergillus oryzae.

Part of the characteristic response in a small-inoculum culture is likely to be due to a decrease in specific rate of oxygen uptake accompanied by an increase in fermentative reactions (production of ethanol and acids). However, the surplus of ethanol and acids formed is small in comparison with the decreased yield of mycelium in small-inoculum cultures. There are undoubtedly other metabolic reactions which promote the effects caused by size of inoculum. It has to be considered not only how much energy (per unit weight carbohydrate used) is made available, but also whether the released energy is used efficiently. There are strong indications that a young culture from a large inoculum is able to utilize energy for synthetic reactions much more efficiently than an older culture of similar origin or a culture from a small inoculum at any stage of growth. Preliminary tests showed that washed mycelium from large-inoculum cultures in the early exponential phase, when suspended in glucose phosphate buffer, showed a considerable increase in cell material in short- 
term tests (1-6 hr.). On the other hand, there was either a decrease or no change in mycelial dry weight when mycelium, similarly treated, was taken from later stages of the exponential phase of large-inoculum cultures, or from any measurable stage of growth of small-inoculum cultures. The higher synthetic ability in young largeinoculum cultures might be due to a greater activity of synthesizing enzymes or perhaps to a more efficient energy transfer from the catabolic to the anabolic enzyme system. This higher assimilation activity, which takes place in a nitrogenfree medium, may lead purely to the formation and accumulation of carbohydrate within the mycelium, as observed originally by Barker (1936) with Prototheca zopfii. On the other hand a more orderly increase of cell material might take place by utilization of nitrogenous components present in the cell. Neither possibility has yet been tested for experimentally. In this context it should be noted that the nitrogen content of the mycelium has been shown to be higher at earlier stages of growth (McIntosh \& Meyrath, 1963); this nitrogen might serve as reserve material.

Part of this work was carried out at the Department of Agricultural Bacteriology and Fermentation, Swiss Federal Institute of Technology, Zürich. The authors are indebted to Miss A. Mohler and Mr G. Geser (Zürich) and Mr J. McElroy (Glasgow) for careful technical assistance rendered. The stimulating interest of Professor E. O. Morris (Glasgow) is greatly appreciated.

\section{REFERENCES}

Barker, H. A. (1936). The oxidative metabolism of the colourless alga, Prototheca zopfii. J. cell. comp. Physiol. 8, 231.

Di Marco, A. (1956). Metabolism of Streptomyces aureafaciens and biosynthesis of chlortetracycline. Giorn. Microbiol. 2, 285.

McIntosh, A. F. \& Meyrath, J. (1963). Size of inoculum and nitrogen metabolism in Aspergillus oryzae. J. gen. Microbiol. 33, 59.

Maxon, W. D. \& Johnson, M. J. (1953). Aeration studies on propagation of baker's yeast. Industr. Engng Chem. 45, 2554.

MEyrath, J. (1962a). Size of inoculum and growth kinetics of moulds. Experientia, 18, 41.

Meyrath, J. (1962b). Problems in fruit juice pasteurization. In Recent Advances in Food Science, p. 117. Ed. by J. Hawthorn and J. M. Leitch. London: Butterworths.

Meyrath, J. (1963). Influence of the size of inoculum on various growth phases in Aspergillus oryzae. Antonie van Leeurwenhoek J. Microbiol. Serol. 29, 57.

MüLler, P. (1957). Untersuchungen über das Wachstum, die Atmung und den intermediären Stoffwechsel von Marasmius putillus (Fr. ex Fr.) Fr. Thesis, Eidgenössische Technische Hochschule, Zürich.

Nilsson, R. (1941). In Die Methoden der Fermentforschung. Ed. E. Bamann and K. Myrbäck 3, 2150. Leipzig: Georg Thieme.

Rolinson, G. N. (1952). Respiration of Penicillium chrysogenum in penicillin fermentations. J. gen. Microbiol. 6, 336.

Sомм, H. (1953). Beiträge zur Kenntnis der Wachstums- und Atmungsphysiologie von Mycelium Radicis atrovirens Melin mit besonderer Berücksichtigung der Stickstoffquelle und einiger Mono-, Di- und Tricarbonsäuren. Thesis, Eidgenössische Technische Hochschule, Zürich.

Stiles, H. R., Peterson, N. H. \& Fred, E. B. (1926). A rapid method for the determination of sugar in bacterial cultures. J. Bact. 12, 427 .

TamiYa, H. (1942). Atmung, Gärung und die sich daran beteiligenden Enzyme von Aspergillus. Advanc. Enzymol. 2, 183.

TemperLI, A. (1956). Thesis, Swiss Federal Institute of Technology, Zürich.

Umbreit, W. W., Burris, R. H. \& Stauffer, J. F. (1949). Manometric Techniques and Tissue Metabolism. Minneapolis: Burgess Publishing Co. 